\title{
ANALYSIS OF OXIDATIVE STRESS MARKERS MALONDIALDEHYDE, GLUTATHIONE, NITRIC OXIDE, AND PRORENIN LEVEL IN PREECLAMPSIA PLACENTAL TISSUES
}

\section{ANI RETNO PRIJANTI ${ }^{1,2}$, NELLY MARISSA ${ }^{3,4}$, RENI PARAMITA ${ }^{1,2}$, SARAH HUMAIRA ${ }^{5}$, ELDESTA NISA NABILA ${ }^{5}$, ANTHONY EKA WIJAYA ${ }^{5}$, ASIYAH NURUL FADILA ${ }^{5}$, YUDITIYA PURWOSUNU ${ }^{6}$}

${ }^{1}$ Department of Biochemistry and Molecular Biology, Faculty of Medicine, Universitas Indonesia, Jakarta, Indonesia 10430. ${ }^{2}$ Department of Biochemistry and Molecular Biology, Centre of Hypoxia and Oxidative Stress Studies, FKUI, Jakarta, Indonesia 10430. ${ }^{3}$ Masters

Programme of Biomedical Sciences, FKUI, Jakarta, Indonesia 10430. ${ }^{4}$ Loka Penelitian dan Pengembangan Biomedis, Provinsi Aceh, Indonesia. ${ }^{5}$ Medical Doctor Program, Faculty of Medicine, Universitas Indonesia, Jakarta, Indonesia 10430. ${ }^{6}$ Department of Obstetric \& Gynaecology, Faculty of Medicine, Universitas Indonesia, Jakarta, Indonesia 10430. Email: aniretno@gmail.com

Received: 07 March 2017, Revised and Accepted: 29 September 2017

\section{ABSTRACT}

Background: Preeclampsia was a syndrome of hypertension proteinuria in pregnant women. In failure of pseudo vasculogenesis, there is persistency of endothelial and smooth muscle cell of vessel wall in spiral artery. Spiral artery could not be emphasis and lead to relative hypoxia, and oxidative stress in placental tissues. Endothelial cell has property to produce nitric oxide (NO) that can dilated vessel. Placenta also produces prorenin, to maintain vascular wall tonicity. Therefore, we want to uncover the property of placenta is there any capacity of prorenin, is that prorenin could overcome the NO level, or is there any depression of NO production, and any oxidative stress.

Methods: This observational study was used case-control design. We search preeclampsia cases during September-December 2015. We used preeclampsia placentas from early and late onset. We collect preeclampsia placentas from Cipto Mangunkusumo and normal placentas from Budi Kemuliaan Hospital. We used 30 preeclampsia placentas and 30 normal placentas. Markers measured were NO and prorenin. NO was measured using colorimetric assay kit (K262-200/ BioVision), and prorenin was measured using human prorenin enzyme-linked immunosorbent assay kit (ab157525/ Abcam). Glutathione (GSH) was measured using Ellman method and malondialdehyde (MDA) using Wills method.

Results: Prorenin concentration between normal and preeclampsia placenta was analyzed using Mann-Whitney and show that there had no significant difference between preeclampsia and normal placentas $(\mathrm{p}=0.23)$. Besides, NO data analyzed using independent $\mathrm{t}$-test show significant differences between preeclampsia and normal placentas $(\mathrm{p}=0.001)$. The difference between normal and preeclampsia GSH concentration was not significant ( $\mathrm{p}=0.757)$, besides the difference between normal and preeclampsia MDA concentration was significant $(\mathrm{p}=0.000)$.

Conclusion: NO concentration in preeclampsia placenta was increase, higher than normal placenta. There was no effect of preeclampsia on prorenin concentration and GSH. There was marked decrease of MDA in preeclampsia placentas.

Keywords: Preeclampsia, Placenta, Nitric oxide, Prorenin.

(c) 2018 The Authors. Published by Innovare Academic Sciences Pvt Ltd. This is an open access article under the CC BY license (http://creativecommons. org/licenses/by/4. 0/) DOI: http://dx.doi.org/10.22159/ajpcr.2018.v11i1.18330

\section{INTRODUCTION}

Maternal mortality rate is still considered to a health problem. In year of 2012 , maternal mortality rate was increased to become $359 / 100,000$ alive birth. Previously, in 2007 it was 228/100,000 alive birth [1]. One of the main causes of maternal mortality was hypertension. Besides, one of the diseases during gestation that suffers hypertension is preeclampsia syndrome.

Preeclampsia syndrome is a symptoms that consists of hypertension and proteinuria during gestation [2]. Incidency of preeclampsia in the world was about $3 \%$ [2]. Otherwise, the ultimate cause of preeclampsia syndrome was still in debatable, but some risk factors were considered to become the background of this syndrome: Antiphospholipid syndrome, gestation history of preeclampsia syndrome in family, diabetes mellitus, nullipara, obesity, over 40 years old, and hypertension [3].

Placenta is important organ to support normal pregnancy, because it becomes a connection between mother and fetus. Placenta was developed since 8-18 weeks of gestation act as modified connecting channel and dilated also unresponsive to vasoconstrictors [4]. In preeclampsia, placentation was proceed uncompletely caused blood pressure increased and had low perfusion. Imbalance between circulate angiogenesis factors and maternal response will determine the clinical symptomes [5].

Nitric oxide (NO) acts as a strong vasodilator in pregnancies. Increase of intravascular lead vascular dilatation and increase of intravascular NO allow placental vessel dilated. Many researchers conducted to measure NO concentration in pregnancies, but the results were still in doubt.

Bonsaffoh in 2015 conducted study to compare serum NO concentration in non-preeclampsia and preeclampsia, showed result increase of serum NO in women with preeclampsia than non-preeclampsia. The elevation especially NO was increased in early onset than late onset [6]. Conversely, Saha in 2013 report that serum NO concentration was decreased in preeclampsia syndrome, this finding was parallel to Rodriguez finding that the decrease of inducible nitric oxide synthase activity (iNOS) in preeclampsia [6-8].

Another vascular marker that could be investigated in preeclampsia was prorenin. Prorenin is part of Renin-Angiotensin-Aldosterone system that mediates hypertension. Some researchers found prorenin in various concentrations in placental tissues of preeclampsia. Therefore, we conduct observation research to reveal the concentration of prorenin compared to some stress oxidative markers in preeclampsia placentas. 


\section{METHODS}

This research was an observational study with cross-sectional design: Case-control. The population was preeclampsia syndrome patient. Samples were placentas of pregnant women indicated preeclampsia that hospitalized at Cipto Mangunkusumo Central Hospital.

Samples collection was according to convenience sampling, 21 preeclampsia cases, and 24 cases without preeclampsia. Placentas that firm to criteria, accepted to this study. Inclusion criteria were preeclampsia placenta. Exclusion criteria were preeclampsia with infection and gestational hypertension.

Placentas samples were collected from delivery room of Cipto Mangunkusumo central Hospital (preeclampsia) and Budi Kemuliaan Hospital Jakarta Indonesia, with inform consent. Samples were kept in deep freezer $-80^{\circ} \mathrm{C}$ at Biochemistry \& Molecular Biology Laboratory, Faculty of Medicine, Universitas Indonesia.

\section{NO measurement}

Sample homogenate was made from $100 \mathrm{mg}$ placental tissue homogenized to be $1 \mathrm{ml}$ in phosphate buffered saline $\mathrm{pH}$ 7.4. NO was measured using Griess colorimetric assay kit. Every $85 \mu \mathrm{l}$ sample homogenate was mixed with $115 \mu \mathrm{lBS}$ pH 7,4 and put into microplate well. Furthermore, add into wells each of $5 \mu$ nitrate reductase and then $5 \mu \mathrm{l}$ enzyme cofactor followed by incubation for $1 \mathrm{~h}$. After incubation, $5 \mu \mathrm{l}$ enhancer was added to each of wells followed by addition of $50 \mu \mathrm{l}$ Griess R1 dan Griess R2 reagent into each of wells. Change of color will appeared in $10 \mathrm{~min}$. Absorbances were measured at $540 \mathrm{~nm}$ wavelength. The result compared with the NO derivatives standard curve.

\section{Glutathione (GSH) measurement}

Reduced GSH was measured using Ellman method as same as LathaLatha research that used this method to determine GSH in carbon tetrachloride liver tissue acute toxicity/injury $[9,10]$. The principle of Ellman reaction: Reduction of Ellman reagent by -SH group to produce the yellow color of 5,5' dithiobis(2-nitrobenzoicacid) [9]. The absorbance was measured at $412 \mathrm{~nm}$ using Varioskan spectrofluorometer. The result was expressed as $\mu \mathrm{g} / \mathrm{mg}$ protein

\section{Malondialdehyde (MDA) measurement}

MDA measurement was done using Wills method. $2 \mathrm{ml}$ of placental homogenate was added with $1 \mathrm{ml} 20 \%$ cold tricarboxylic acid and mixed using vortex for $1 \mathrm{~min}$ followed by centrifugation at $1500 \mathrm{~g}$ for $10 \mathrm{~min}$. Supernatant liquid was taken and stored at $-85^{\circ} \mathrm{C}$ (deep freezer) before used. $200 \mu \mathrm{L}$ supernatant liquid was added into $2 \mathrm{ml}$ of thiobarbituric acid and boiled for $10 \mathrm{~min}$ in boiling water. After boiled the mixture let stay to be cold at room temperature. The absorbance was measured at $530 \mathrm{~nm}$ using an optical spectrophotometer. The result was expressed as $\mathrm{nmol} / \mathrm{mg}$ protein $[9,11]$.

\section{Measurement of prorenin protein}

Prorenin protein was measured using enzyme-linked immunosorbent assay kit. Each of $100 \mu \mathrm{l}$ sample homogenate was added into wells, and shaked, followed centrifugation for $30 \mathrm{~min}$. Furthermore, wells washed with buffer. After washing, $100 \mu \mathrm{l}$ prorenin antibody was added into each well, and incubated for $30 \mathrm{~min}$. After washing $90 \mu \mathrm{l}$ substrate was added. After $30 \mathrm{~min}$ incubation stop solution was added to stop the reaction. Absorbances of NO derivatives were measured at $450 \mathrm{~nm}$ of wavelength.

\section{Statistical analysis}

Normality and homogeneity of data show that our data were not normal and not homogenous; therefore, we used Mann-Whitney and Kruskal-Wallis analysis.

\section{RESULTS AND DISCUSSION}

\section{NO measurement}

NO derivatives were measured using colorimetric method. Average concentration of NO-derivatives in preeclampsia was $12.532 \mu \mathrm{M}$, besides normal was $12.083 \mu \mathrm{M}$. Statistical analysis using Mann-Whitney show significant differences between preeclampsia and normal placentas, $p=0.002$. Although in preeclampsia placentas NO concentrations were higher than a normal pregnancy.

\section{Placental prorenin}

Placental prorenin average concentration of preeclampsia was $5.7 \times 10^{-5} \mathrm{ng} / \mathrm{ml}$. On the other, prorenin average concentration of normal placenta was $5.3 \times 10^{-5} \mathrm{ng} / \mathrm{ml}$. Mann-Whitney statistical analysis shows that there was no significant difference of prorenin between preeclampsia and normal placentas $(\mathrm{p}=0.884)$.

Preeclampsia is a syndrome signed by hypertension and proteinuria, divided into two steps. First step appear before 20 weeks of gestation, there is an uncompleted changing in spiral is arteries that caused failure of placentation. Failure of placentation caused chronic uteroplacental ischemia. Second step, the systemic signs expressed according to maternal inflammation, imbalance of angiogenesis antiangiogenesis [4,9]. Some of angiogenesis markers could be detected were vascular endothelial growth factor, but we focus on prorenin and NO. Marker for hypoxia and oxidative stress caused by hypoxia were MDA, GSH, and enzymes such as superoxide dismutase, peroxidase, thioredoxin system, and catalase; we focus on MDA and GSH.

In this study, we found that preeclampsia placentas NO concentration significantly higher than non-preeclampsia (normal) placentas (Fig. 1). Shaamash et al. report showed that there was higher NOS activity and NO production in preeclampsia and preeclampsia [13]. Besides, Adu-bonsaffoh et al. also report that there was an increase of NO in preeclampsia higher than non-preeclampsia [6]. Otherwise, Ehsanipoor found that there was a decreased of placental NO and heme oxygenase-I. Furthermore, Ehsanipoor also found that the decrease of NO was influenced by placental dimethylarginine dimethylaminotransferase (DDAH-H and DDAH-II) [14]. Another study, No et al. report that preeclampsia e-NOS expression was lower compared to normal placenta [15].

Nitric oxide is a strong vasodilator act on placental vessel relaxation lead to adequate placental blood flow. This was proofed by inhibition of NO will increased blood pressure of uterine arteries [16]. NO was produced by eNOS and iNOS. In gestation, eNOS expression was increased, serum NO concentration was increased according to gestational age, and will be decreased into concentration before gestation after 12 weeks after birth [17]. Decreased NO concentration in circulation and placental was conversely to the increased concentration of $\mathrm{H}_{2} \mathrm{O}_{2}$ marker of oxidative stressed in placentas [18].

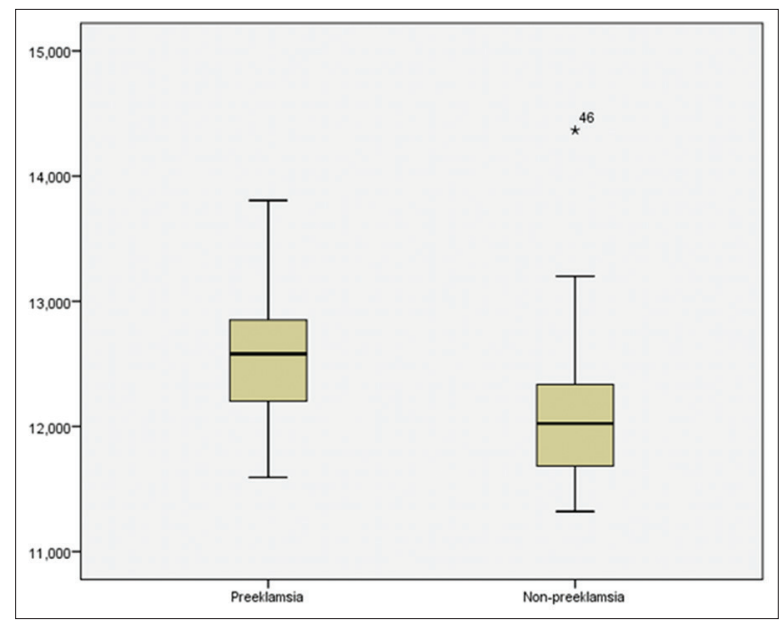

Fig. 1: Nitric oxide expression in placentas $(\mu \mathrm{M})$. There was a significant difference of NO between normal and preeclampsia placentas $(p=0.001)$ 


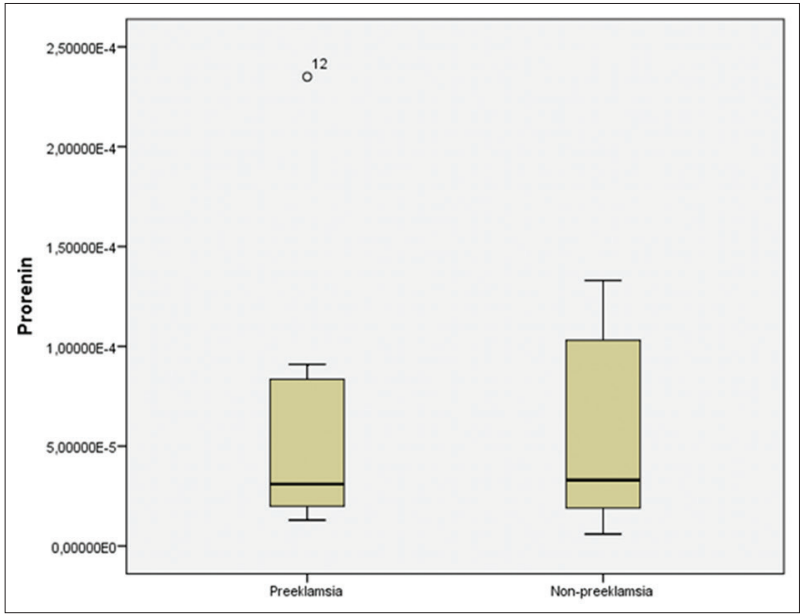

Fig. 2: Prorenin protein expression of placental tissue (ng/ml). There was no significant difference of prorenin protein concentration between preeclampsia and normal placenta $(\mathrm{p}=\mathbf{0 . 2 3 )}$

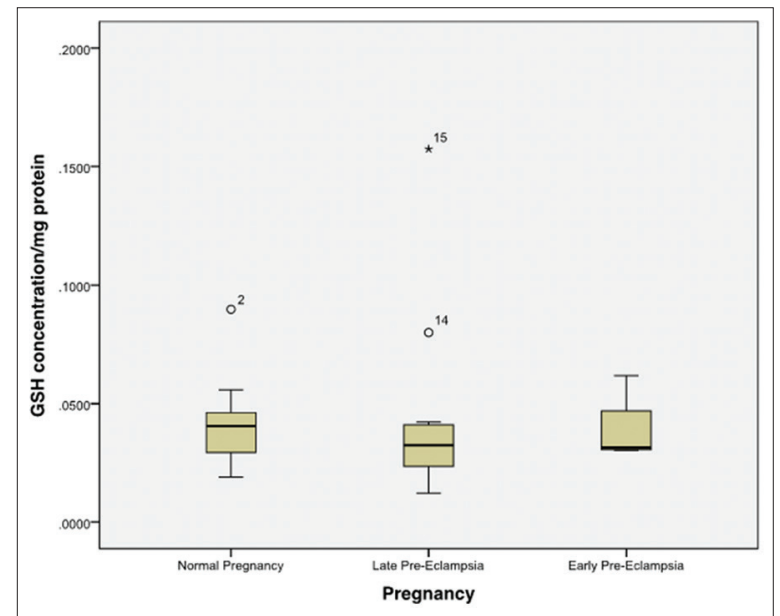

Fig. 3: Glutathione (GSH) concentration in placenta. There was no significant difference of GSH between normal pregnancy, late, and early preeclampsia placentas $(\mu \mathrm{g} / \mathrm{mg})(K r u s k a l-W a l l i s, ~ p=0.757)$

In a normal pregnancy, prorenin mRNA relative expression was found in chorion, decidua, and placenta [19]. Gestation without complication of hypertension, serum prorenin concentration was increase following the gestational age. In the third trimester, the decrease of prorenin concentration was correlated to complication of gestational hypertension [20]. In this study, preeclampsia placental prorenin concentration had no significant difference than normal, but tends to decreased.

Renin-angiotensin system play role in blood pressure control mechanism and electrolyte balance. Prorenin is an inactive precursor of renin and has concentration 10 times higher than renin. Prorenin activation mechanism to be renin needs proteolytic cleavage by protease, and also by a non-proteolytic mechanism through regulation of $\mathrm{pH}$ and temperature [21].

We found that MDA concentration in early and late preeclampsia tissues was very low. We suggest that in preeclampsia placenta the amount of reactive oxygen species was very low (Fig. 4) and not enough to stimulate signal transduction for placental growth and development. However, GSH level in placentas shows no difference between normal and preeclampsia. We assumed that GSH level was not change because there was no GSH usage by ROS.

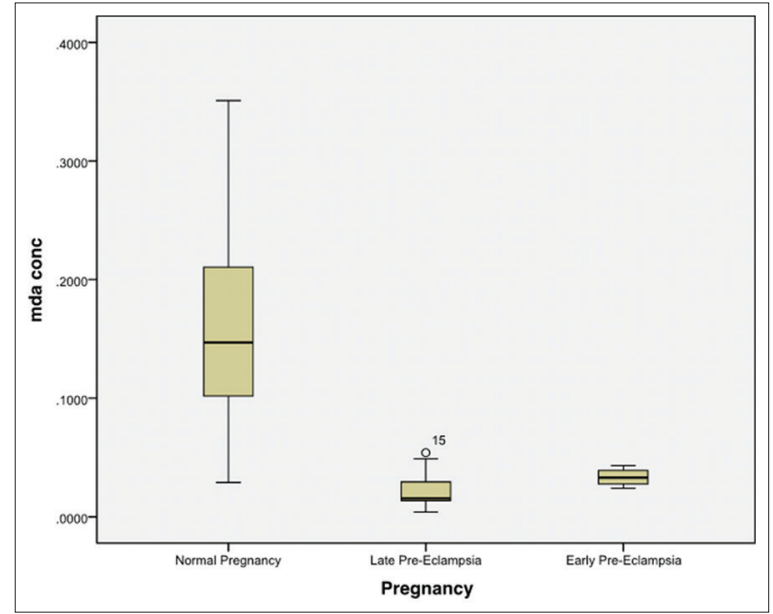

Fig. 4: Malondialdehyde concentration in placenta. Fig. 4 showed that MDA of preeclampsia placentas reduced significantly in preeclampsia tissue than normal placental $(\mathrm{nM} / \mathrm{mg})(\mathrm{p}=0.000)$

\section{CONCLUSION}

Concentration of nitric oxide of preeclampsia was higher significantly than normal placenta. There was no significant difference of prorenin between preeclampsia and normal placenta, and decrease of GSH usage that may cause by decrease markedly of ROS production.

\section{ACKNOWLEDGMENTS}

We wish to express our gratitude to Directorate of Research and Public Service University of Indonesia, for the PITTA 2016 Research Grant.

\section{REFERENCES}

1. Kementerian Kesehatan Republik Indonesia. Profil Kesehatan Indonesia 2014. Jakarta: Kementerian Kesehatan Republik Indonesia; 2015. p. 40.

2. Hutcheon JA, Lisonkova S, Joseph KS. Epidemiology of pre-eclampsia and the other hypertensive disorders of pregnancy. Best Pract Res Clin Obstet Gynaecol 2011;25(4):391-403.

3. English FA, Kenny LC, McCarthy FP. Risk factors and effective management of preeclampsia. Integr Blood Press Control 2015;8:7-12.

4. Redman CW. Preeclampsia: A multi-stress disorder. Rev Med Interne 2011;32 Suppl 1:S41-4.

5. Scioscia M, Karumanchi SA, Goldman-Wohl D, Robillard PY. Endothelial dysfunction and metabolic syndrome in preeclampsia: An alternative viewpoint. J Reprod Immunol 2015;108:42-7.

6. Adu-Bonsaffoh K, Antwi DA, Obed SA, Gyan B. Nitric oxide dysregulation in the pathogenesis of preeclampsia among Ghanaian women. Integr Blood Press Control 2015;8:1-6.

7. Saha T, Halder M, Das A, Das SK. Role of nitric oxide, angiogenic growth factors and biochemical analysis in preeclampsia. Indian $\mathrm{J}$ Biochem Biophys 2013;50(5):462-6.

8. Juan R, Medrano-cortés E, Franco-trejo CS. Inducible nitric oxide synthase in the placenta of pregnant women with preeclampsia. Int Online Med Conf Obstet Gynecol 2015;8:1-5.

9. Latha B, Latha MS. Antioxidant and curative effect of Leucas Aspera methanolic extract against Carbon tetrachloride induce acute liver injury in rats. Int J Pharm Pharm Sci 2013;5(1):374-8

10. Geetha P, Kumar BL, Indra U, Sheetal BP. Role of antioxidant and Myeloperoxidase level in 7,12-dimethylbenz (A) anthracene induced experimental rat model: Evidence for oxidative damage in active ulcerative colitis. Int J Pharm Pharm Sci 2017;9(3):282-6.

11. Lovric J, Mesic M, Macan M, Koprivanas M, Kelava M, Bradamante V. Measurement of malondialdehyde (MDA) level in rat plasma after simvastatin treatment using two different analytical methods. Period Biol 2008;110(1):63-7.

12. Rodriguez M, Moreno J, Hasbun J. RAS in pregnancy and preeclampsia and eclampsia. Int J Hypertens 2012;2012:739274.

13. Shaamash AH, Elsonosy ED, Zakhari MM, Radwan SH, El-Dien HM. Placental nitric oxide synthase (NOS) activity and nitric oxide (NO) 
production in normal pregnancy, pre-eclampsia and eclampsia. Int $\mathbf{J}$ Gynaecol Obstet 2001;72(2):127-33.

14. Ehsanipoor RM, Fortson W, Fitzmaurice LE, Liao W, Wing DA, Chen $\mathrm{D}$, et al. Nitric Oxide and carbon monoxide production and metabolism in preeclampsia. Reprod Sci 2012;20(5):542-8.

15. Lee CN, Chang SW, Cho NH, Cho SH. Nitrous oxide synthase expression in placenta of preeclampsia. J Korean Med Sci 1997;12(6):532-8.

16. Barron C, Mandala M, Osol G. Effects of pregnancy, hypertension and nitric oxide inhibition on rat uterine artery myogenic reactivity. J Vasc Res 2010;47(6):463-71.

17. Choi JW, Im MW, Pai SH. Nitric oxide production increases during normal pregnancy and decreases in preeclampsia. Ann Clin Lab Sci 2002;32(3):257-63.
18. Aris A, Benali S, Ouellet A, Moutquin JM, Leblanc S. Potential biomarkers of preeclampsia: Inverse correlation between hydrogen peroxide and nitric oxide early in maternal circulation and at term in placenta of women with preeclampsia. Placenta 2009;30(4):342-7.

19. Pringle KG, Zakar T, Yates D, Mitchell CM, Hirst JJ, Lumbers ER. Molecular evidence of a (pro)renin/ (pro)renin receptor system in human intrauterine tissues in pregnancy and its association with PGHS-2. J Renin Angiotensin Aldosterone Syst 2011;12(3):304-10.

20. Mikami Y, Narita T, Takai Y, Baba K, Matsuoka K. The Progression of serum prorenin concentration during pregnancy. Hypertension 2014;166(3):1-6.

21. Nabi AH, Suzuki F. Biochemical properties of renin and prorenin binding to the (pro)renin receptor. Hypertens Res 2010;33(3):91-7. 